\title{
Are Tonsils and Adenoids Secondary Reservoirs for Helicobacter pylori in Children? Why it Matters!!
}

\author{
Abdullah M Nasrat ${ }^{1,{ }^{*}}$, Salwa AM Nasrat ${ }^{2}$, Randa M Nasrat ${ }^{3}$ and Mohammad M Nasrat ${ }^{3}$ \\ ${ }^{1}$ Department of Surgery, Balghsoon Clinic, Jeddah, KSA \\ ${ }^{2}$ Department of Physical Therapy, Cardiac Surgery Academy, Cairo, Egypt \\ ${ }^{3}$ Department of Internal Medicine, Helwan General Hospital, Helwan, Egypt
}

*Corresponding author: Abdullah M Nasrat, Department of Surgery, Balghsoon Clinic, Jeddah, PO Box 5261 KSA-21573, Tel: +966 (012) 667 3645; E-mail: abdullahalnasrat@hotmail.com

Rec date: September 29, 2015 Acc date: October 19, 2015 Pub date: October 23, 2015

Copyright: ( 2015 Nasrat AM, et al. This is an open-access article distributed under the terms of the Creative Commons Attribution License, which permits unrestricted use, distribution, and reproduction in any medium, provided the original author and source are credited.

\begin{abstract}
The study aimed at demonstration of the possible existence of Helicobacter pylori in tonsils and adenoids and its possible risk sequences.

The stomach wall represents the main and commonest habitat for $H$. pylori since an immemorial time; in a way indicating that mucosa of the stomach is the structure of the body that can recognize that stomach bacterium. Therefore; migration of $H$. pylori outside the stomach could encode autoimmunity. Tonsils and adenoids are lately discovered as secondary reservoirs for $H$. pylori in children. Further reports have confirmed the association of adenotonsillar hypertrophy with cytotoxin-associated gene A (cagA) positive $H$. pylori strains, and emphasized that cagA of $H$. pylori encodes high immunogenicity.
\end{abstract}

Migration of $H$. pylori into the circulation could be an open gate for systemic complications; although $H$. pylori bacteremia is not a recognized behavior of a bacterium used to colonize the stomach, yet $H$. pylori bacteremia is clearly reported in literature. $H$. pylori can reside in dental plaques where it can feed on remnants of food in the mouth or bleeding from gums. Therefore; surgery on hypertrophied tonsils while migrating $H$. pylori strains exist around could attract these strains to gain feeding on the resulting oozing tonsil's surgical bed with the possible potential risk and sequels of $H$. pylori bacteremia.

30 children aged 10-12 years with frank symptoms and family history of $H$. pylori dyspepsia scheduled for surgery because of hypertrophy of tonsils and adenoids were included in the study. They were divided into three equal groups; group 1 followed natural $H$. pylori eradication therapy and group 2 underwent surgery while group 3 followed antibiotic therapies before surgery. Existence of $H$. pylori strains was proved in children and parents by specific tests (urea breath test and $H$. pylori fecal antigen test).

All children and parents were found positive for colonic $H$. pylori strains. Urea breath test was positive in most children. Adenoid/tonsil surgical specimens were mostly positive for $H$. pylori DNA. Regression of hypertrophy of tonsils was demonstrated in most children of the natural therapy first group and 7 of 10 children escaped surgery.

On conclusion, existence of $H$. pylori should be ruled out and eliminated from the throat by natural measures before surgery of hypertrophied tonsils demonstrating no suppuration or inflammation.

Keywords: Helicobacter pylori; Tonsils; Adenoids

\section{Introduction}

Helicobacter pylori remains a challenging worldwide medical problem due to its extreme widespread prevalence and its close relation to many medical challenges [1-4]. About $50 \%$ of adults in the developed and $80-90 \%$ in the developing countries are estimated to be affected by $H$. pylori $[5,6]$. Existence of $H$. pylori is typically life-long unless treated. It has got a clear age-related prevalence; increasing from $10 \%$ in those younger than 30 until it reaches a plateau of about $60 \%$ in those older than age of 60 or even to about $70 \%$ at 50 years of age in higher risk areas [1,7]. It has been estimated that 1:30-1:60 of the UK population die from an $H$. Pylori related disease [8,9]. All these reasons contributed to the world's attitude that $H$. Pylori eradication is a necessary attempt.

Although the eradication regimens do eradicate $H$. pylori from the stomach; the emergence of antibiotic-resistant $H$. pylori strains and the severe side effects are major drawbacks of these treatments [10]. More efficient, economic and friendly drugs need to be developed.

Moreover, the flare up of a lot of medical challenges related to $H$. pylori through immune or different unknown reasons indicates that the current combined antibiotic $H$. pylori eradication therapy is not an effective measure to control all the problems caused by the stomach bacterium [11]. The auto-immune medical challenges related to $H$. pylori per se are sufficient to render the matter that $H$. pylori can reside hidden somewhere in the body be taken seriously. 
Concerning the pathologic behavior, $H$. pylori colonized the stomach since an immemorial time; [8] as if both the stomach and $H$. pylori used to live together in peace harmless to each other that would further indicate that $H$. pylori could be a natural bacterium, except until the antibiotics violence towards it that has possibly rendered the bacterium wild in attitude and sequences instead of getting rid of it.

In children, Existence of $H$. pylori starts trans-familial during early childhood, and the $H$. pylori strain is often identical with that of parents. Interestingly, children maintain the same strain genotype even after moving to a different environment [8]. Elimination of $H$. pylori from the stomach in children could be probably common due to the frequent antibiotic use for other reasons; yet, trans-familial recurrence and recurrence via dental plaques still resemble a challenge [8-11]. It should be also worthy to consider that the frequent use of antibiotics in children could contribute in alteration of the behavioral attitude of $H$. pylori inside the body.

Moreover, tonsils and adenoids are lately discovered as secondary reservoirs for $H$. pylori in children. It has been shown that there is high rate of $H$. pylori colonization in the tonsil, adenoid tissues and the middle ear effusion with further indication that the organism might be involved in pathogenesis of otitis media with effusion. Further reports have confirmed the association of adenotonsillar hypertrophy with cytotoxin-associated gene A (cagA) positive $H$. pylori strains, and emphasized that cagA of $H$. pylori encodes a highly immunogenic and virulence-associated protein; the presence of this virulent gene in the tonsils and adenoids tissues could affect clinical outcome in many patients [12-15].

Dietary vinegar (acetic acid 5\%) has been recently demonstrated as dramatic, effective and decisive solution for all the challenges and medical problems related to $H$. pylori including eradication and reinfection $[16,17]$.

\section{Aim}

Demonstration of the possible existence of $H$. pylori in tonsils and adenoids and its possible risk sequences.

\section{Design and Settings}

Prospective study done in Balghsoon Clinics in Jeddah, Saudi Arabia between October 2011 and May 2013.

\section{Patients and Methods}

The study included 30 children scheduled for surgery because of hypertrophy of tonsils and adenoids divided in three equal groups, their age ranged between 10-12 years and they were having frank symptoms and family history of $H$. pylori dyspepsia.

Existence of H. pylori was proved in children by sensitive specific tests $(H$. pylori fecal antigen and urea breath tests) while existence of colonic $H$. pylori strains in parents was proved by $H$. pylori fecal antigen test [8]. The cases were included according to the clinical findings of the tonsils so that the tonsils are the seat of hypertrophy without inflammation, discharge or suppuration unlike acute follicular tonsillitis; it was aimed to rule out as possible any possible effect of the swallowed discharge or pus from tonsils to cause abdominal symptoms in children.

Children of the first group followed natural therapy for eradication of $H$. pylori from the colon employing calculated doses of the natural senna purge extract followed by colon care by having a vinegar-mixed salad beside meals for one week. Elimination of $H$. pylori strains from their upper respiratory region was done by mouth wash or gargling with diluted white vinegar and inhaling the smell of vinegar via the nose. Eradication of colonic $H$. pylori strains in parents of the first group was done by the classical amounts of the natural senna purge [16-18].

Children of the second group underwent surgical adenotonsilectomy while children of the third group were treated with antibiotics. The second and third groups followed the protocol of another research team as antibiotics do not apply in the natural therapy concept of the research team of this study; the results of the second and third groups were only employed for comparative reasons. DNA extraction was done for the surgical adenoid/tonsil specimens. Children of the first group were free to lead their regular life style except restriction of out-side home meals in order to avoid $H$. pylori recurrence. Eradication of $H$. pylori in children and parents of the first group was confirmed by the same specific tests after one week of natural therapy.

\section{Results}

All children and parents were found positive for existence of colonic $H$. pylori strains and its eradication from the colon in the first group after the natural therapy was confirmed successful according to $H$. pylori fecal antigen testing. Urea breath test was positive in 7 children in group 1 and 2 and in 6 children in the third group.

Nine children in the first group showed regression of adenoid/ tonsils hypertrophy, relief of throat symptoms and relief of both abdominal upsets and constipation; seven of them escaped surgery while three underwent surgery but their adenoid/tonsils specimens were negative for $H$. pylori DNA extracts with minimal lymphocytic infiltration in histological assessment and rather average distribution of lymphoid follicles simulating that of normal tonsil's tissue.

H. pylori DNA was positive in adenoid/tonsil specimens of 9 children in group 2 and the histopathology of these specimens showed lymphoid follicles with profuse lymphocytic infiltration. Children of this group did not show any improvement of abdominal symptoms or constipation.

The children of the third group showed recurrent attacks of adenotonsilitis and had to repeat the antibiotic therapy three times; nine of them underwent surgery and all specimens were positive for $H$. pylori DNA with the same histopathology of lymphoid follicles and profuse lymphocytic infiltration as that of the second group. Children of this group did not show also any real improvement in their dyspeptic symptoms.

The seven children of the first group who escaped surgery were followed up for 6 months to assess incidence of recurrence; only five of them continued the follow up, they showed throat inflammation once or twice but without recurrence of hypertrophy of tonsils or adenoids.

\section{Ethical Considerations}

An informed signed consent was taken from all parents; Parents of the first group were made aware about safety of the natural remedies employed for their children and them. The parents of the first group were free to render their children quit the study whenever they like. 


\section{Discussion}

The stomach wall represents the main and commonest habitat for $H$. pylori since an immemorial time; in a way indicating that mucosa of the stomach is the structure of the body that can recognize that stomach bacterium while other tissues do not. Therefore; migration of $H$. pylori outside the stomach under the influence of antibiotic violence, abuse of antibiotic or misbehavior in food habits will render it foreign structures to the tissues and becoming a poison or a source of illness by encoding autoimmunity [8].

Sufficient reports have confirmed the association of adenotonsillar hypertrophy with cytotoxin-associated gene A (cagA) positive $H$. pylori strains, and emphasized that cagA of $\mathrm{H}$. pylori encodes a highly immunogenic and virulence-associated protein; the presence of this virulent gene in the body could affect clinical outcome in many children [12-15].

$H$. pylori is not just a bad bug in all instances; normal-behavior $H$. pylori is just lying juxta-mucosal under the gastric mucus layer and is harmless, it is even beneficial and protective against low gastric acidityrelated carcinoma of the cardia of stomach. Sticking and embedding within folds of gastric mucosa caused by the influence of increased gastric acidity due to misbehavior in food habits is not a normal behavior of $H$. pylori; it is a reason of irritation to gastric mucosa that clearly causes histological lymphocytic gastritis [8,19-21].

The mucosal lymphocytic response to $H$. pylori significantly increases the risk of gastric mucosa associated lymphoid tissue (MALT) lymphoma as the vast majority of gastric MALT lymphoma patients are affected with $H$. pylori. Interestingly; both $H$. pylori and MALT lymphoma are so linked as if they were almost born simultaneously. The normal stomach is devoid of organized lymphoid tissue; it was shown that lymphocytic gastritis and lymphoid follicles develop in response to $H$. pylori, and the formed lymphoid tissue is morphologically identical with normal MALT. Furthermore; it was found that eradication of $H$. pylori from the stomach with antibiotics alone resulted in regression of gastric MALT lymphoma in $75 \%$ of patients, and those patients have shown sustained clinical remission of their lymphomas $[8,22]$.

Therefore; the lymphocytic response to $H$. pylori could clearly account for the hypertrophy of tonsils and adenoids which has been confirmed in the results of histopathology of the surgical specimens of the second and third groups of the study. The sustained regression of gastric MALT lymphoma after antibiotic eradication of $H$. pylori from the stomach could explain the absence of $H$. pylori DNA and the minimal lymphocytic infiltration in histopathology in the adenoid/ tonsils specimens of the three children in the first group who underwent surgery after one week of natural therapy for elimination of abnormal-behavior $H$. pylori strain from the throat, stomach and colon. This suggestion is supported by findings that confirm the direct lethal effect of dietary white vinegar (acetic acid 5\%) on H. pylori and its decisive influence in elimination of the bacterium $[16,17]$.

H. pylori feeds on remnants of food to gain energy from pyruvate metabolism via the effect of pyruvate dehdrogenase complex enzyme and to produce ammonia from organic urea by the splitting action of urease enzyme $[8,18]$. $H$. pylori can reside in dental plaques as a secondary reservoir constituting a source of gastric recurrence with $H$. pylori where it can feed on remnants of food in the mouth or bleeding from gums [23]. Migration of $H$. pylori into the circulation could be an open wide hell of systemic complications; although $H$. pylori bacteremia is not a recognized behavior of a bacterium used to colonize the stomach, yet $H$. pylori bacteremia is clearly reported in literature [24]. H. pylori DNA was detected in the peripheral blood of patients with peptic ulcer or gastritis where the bacterium possibly found its way to the circulation via erosions in the ulcer or the inflamed gastric mucosa [25] Between possibility and controversy, the relation of $H$. pylori and multiple sclerosis was discussed in literature [26]. Accordingly, invasion of $H$. pylori into the circulation does necessarily indicate an aggressive attitude and sequels in all instances which could further indicate that $H$. pylori might not be by its own pathologic in nature. As long as $H$. pylori could reach the throat causing hypertrophy of tonsils and adenoids to the extent of indicating surgery, the resulting surgical tonsil's bed could attract $H$. pylori to feed on its oozing raw surface and hypothetically constituting a port for the panic migrating strains of $H$. pylori to creep into circulation with its potential risk and sequels.

Existence of extra-gastric strains of $H$. pylori in the tonsils and adenoids would also carry the risk of encoding autoimmunity; idiopathic thrombocytopenic purpura and childhood diabetes are critical elements of $H$. pylori-related autoimmune challenges in children $[27,28]$.

Dietary vinegar (acetic acid 5\%) has been proved to be dramatically effective towards all the medical challenges related to $H$. pylori [16,17,29-31]. The complex nutritional requirements of $H$. pylori are achieved through its unique energy metabolism, which exhibits characteristic sites. These sites can be considered as targets that should attract any attempts to fight the organism [32,33]. As acetate is demonstrated as an end product among the metabolic pathway of $\mathrm{H}$. pylori; [34,35] this means that addition of acetic acid in the atmosphere around $H$. pylori could compromise the energy metabolism of $H$. pylori, or interfere with the organism's respiratory chain. This suggestion is supported by the fact that the major routes of generation of energy for $H$. pylori are via pyruvate and the activity of the pyruvate dehydrogenase complex is controlled by the rules of product inhibition and feedback regulation [36]. It is further supported by the observation that addition of pyruvate to different solid culture media was found to inhibit bacterial growth, and this inhibition was attributed to accumulation of acetate and formate [35,36]. As the matter includes interference of energy metabolism, an immediate lethal effect on $H$. pylori could be considered.

The value of this study lies in the real chance it offers for many children with hypertrophied tonsils and adenoids to escape unnecessary surgery by following simple measures. It also helps to avoid immune complications related to $H$. pylori in children and to avoid a potential risk of the grave $H$. pylori bacteremia in case throat surgery is done whilst a highly motile bacterium exists around the medium.

Antibiotics are seldom effective against extra-gastric $H$. pylori strains; [18,36] antibiotics might not even affect gastric strains except forcing them to migrate outside the stomach as suggested by the creep up of new strains in different location of the body with development of new symptoms. This could explain the detection of $H$. pylori DNA and persistence of a profuse lymphocytic infiltration in the adenoid/tonsils specimens of the third group of children who followed antibiotic therapy and underwent surgery next to antibiotics.

It is worthy to mention that while antibiotics are seldom effective against extra-gastric $H$. pylori strains; $[18,36]$ a potent natural purgative is the only measure to eradicate $H$. pylori strains migrated to the colon, otherwise; these strains would remain in the colon for life [11,16-18]. 


\section{Conclusion}

Migration of $H$. pylori to tonsils and adenoids rendering them secondary reservoirs for it, is a true medical fact which should be considered with great attention as it carries a lot of serious potential and actual risk. Existence of $H$. pylori should be ruled out and eliminated from the throat by natural measures before surgery of hypertrophied tonsils showing no suppuration or inflammation.

\section{Acknowledgements}

The study appreciates the facilities and time allowed by Balghsoon Clinics in Jeddah/Saudi Arabia. The continuous support offered by Abdul-Aziz Al-Sorayai Investment Company (ASIC) in Jeddah/Saudi Arabia, the scientific and emotional support of Dr Ahmed S. Balghsoon and the brotherhood friendly continued encouragement of Mr. Abdul-Aziz Al-Sorayai are extremely valued and appreciated.

\section{References}

1. Andreoli TE (2001) Cecil Essentials of Medicine. WB Saunders Company 5: 334 .

2. Fendrick AM (2000) The role of economic evaluation in the diagnosis and treatment of Helicobacter pylori infection. Gastroenterol Clin North Am 29: 837-851.

3. Groeneveld PW, Lieu TA, Fendrick AM, Hurley LB, Ackerson LM, et al. (2001) Quality of life measurement clarifies the cost-effectiveness of Helicobacter pylori eradication in peptic ulcer disease and uninvestigated dyspepsia. Am J Gastroenterol 96: 338-347.

4. Baron S (2000) medical microbiology. Churchill Livingstone 4: 346.

5. Versalovic J (2003) Helicobacter pylori. Pathology and diagnostic strategies. Am J Clin Pathol 119: 403-412.

6. Strand M, Presecki V, Babus V (2002) Epidemiology of Helicobacter pylori infection. Lijec Vjesn Sep 124 Suppl 1: 5-9.

7. Asaka M (2003) [Epidemiology of Helicobacter pylori infection in Japan]. Nihon Rinsho 61: 19-24.

8. Farinha P, Gascoyne RD (2005) Helicobacter pylori and MALT lymphoma. Gastroenterology 128: 1579-1605.

9. Moayyedi P, Axon AT (1998) Is there a rationale for eradication of Helicobacter pylori? Cost-benefit: the case for. Br Med Bull 54: 243-250.

10. Ge Z (2002) Potential of fumarate reductase as a novel therapeutic target in Helicobacter pylori infection. Expert Opin Ther Targets 6: 135-146.

11. Unver S, Kubilay U, Sezen OS, Coskuner T (2001) Investigation of Helicobacter pylori colonization in adenotonsillectomy specimens by means of the CLO test. Laryngoscope 111: 2183-2186.

12. Yilmaz T, Ceylan M, Akyön Y, Ozçakýr O, Gürsel B (2006) Helicobacter pylori: a possible association with otitis media with effusion. Otolaryngol Head Neck Surg 134: 772-777.

13. Cirak MY, Ozdek A, Yilmaz D, Bayiz U, Samim E, et al. (2003) Detection of Helicobacter pylori and its CagA gene in tonsil and adenoid tissues by PCR. Arch Otolaryngol Head Neck Surg 129: 1225-1229.

14. Bulut Y, Agacayak A, Karlidag T, Toraman ZA, Yilmaz M (2006) Association of cagA+ Helicobacter pylori with adenotonsillar hypertrophy. Tohoku J Exp Med 209: 229-233.

15. Nasrat AM (2005) Helicobacter pylori, an alternate natural remedy for symptomatic relief and spontaneous eradication. International Saudi Symposium of Pediatric Hematology / Oncology
16. Nasrat AM, Nasrat SAM, Nasrat RM (2015) An alternate natural remedy for symptomatic relief of Helicobacter pylori dyspepsia. General Med J 3: 1000200 .

17. Nasrat AM (2009) The world misconception and misbehavior towards Helicobacter pylori is leading to major spread of illness. The 7th AntiAging Medicine World Congress, Monte-Carlo, Monaco.

18. Volk WA, Gebhardt BM, Hammarskjold M-L, Kadner RJ (1996) Essential of Medical Microbiology Lippincott Raven 5: 377.

19. Copie-Bergman C, Locher C, Levy M, Chaumette MT, Haioun C, et al. (2005) Metachronous gastric MALT lymphoma and early gastric cancer: is residual lymphoma a risk factor for the development of gastric carcinoma? Ann Oncol 16: 1232-1236.

20. Gürbüz AK, Ozel AM, Yazgan Y, Celik M, Yildirim S (2003) Ora colonization of Helicobacter pylori: risk factors and response to eradication therapy. South Med J 96: 244-247.

21. Ndawula EM, Owen RJ, Mihr G, Borman P, Hurtado A (1994) Helicobacter pylori bacteraemia. Eur J Clin Microbiol Infect Dis 13: 621.

22. Huang Y, Fan XG, Tang ZS, Liu L, Tian XF, et al. (2006) Detection of Helicobacter pylori DNA in peripheral blood from patients with peptic ulcer or gastritis. APMIS 114: 851-856.

23. Prasad H, Krishnaprasad MS, Karnaker VK (2008) Therapeutic induction of Helicobacter pylori bacteraemia in multiple sclerosis: how far from reality? Med Hypotheses 71: 610-611.

24. Nasrat AM, Nasrat SM, Nasrat RM (2015) An influence of Helicobacter pylori in thrombocytopenia in children. Int J Recent Scientific Res 6: 5052-5054.

25. Nasrat AM, Nasrat SAM, Nasrat RM (2015) The challenge of childhood diabetes. General Med J 3: 1000193.

26. Nasrat SAM, Nasrat RM, Nasrat MM (2015) The dramatic spread of diabetes mellitus worldwide and influence of Helicobacter pylori. General Med J 3: 159-162.

27. Nasrat SAM, Nasrat AM (2015) An alternative approach for the rising challenge of hypertensive illness via Helicobacter pylori eradication. Cardiol Res 6: 221-225.

28. Nasrat RM, Nasrat MM, Nasrat AM (2015) Improvement of idiopatic cardiomyopathy after colon clear. J Cardiol Res6: 249-254.

29. Mendz GL, Hazell SL, Burns BP (1993) Glucose utilization and lactate production by Helicobacter pylori. J Gen Microbiol 139: 3023-3028.

30. Mendz GL, Hazell SL (1993) Fumarate catabolism in Helicobacter pylori. Biochem Mol Biol Int 31(2): 325-32.

31. Mendz GL, Hazell SL, van Gorkom L (1994) Pyruvate metabolism in Helicobacter pylori. Arch Microbiol 162: 187-192.

32. Hughes NJ, Clayton CL, Chalk PA, Kelly DJ (1998) Helicobacter pylori porCDAB and oorDABC genes encode distinct pyruvate:flavodoxin and 2-oxoglutarate:acceptor oxidoreductases which mediate electron transport to NADP. J Bacteriol 180: 1119-1128.

33. Berg JM, Tymoczko JL, Stryer L (2002) Biochemistry (5thedn). WH Freeman and Company p. 480.

34. Midolo PD, Lambert JR, Hull R, Luo F, Grayson ML (1995) In vitro inhibition of Helicobacter pylori NCTC 11637 by organic acids and lactic acid bacteria. J Appl Bacteriol 79: 475-479.

35. Mendz GL, Ball GE, Meek DJ (1997) Pyruvate metabolism in Campylobacter spp. Biochim Biophys Acta 1334: 291-302.

36. Grünberger B, Wöhrer S, Streubel B, Formanek M, Petkov V, et al. (2006) Antibiotic treatment is not effective in patients infected with Helicobacter pylori suffering from extragastric MALT lymphoma. J Clin Oncol 24: $1370-1375$. 